\title{
MRS Co-sponsors Meetings on Ion Beams and Semiconductor Based Heterostructures
}

Conference on Semiconductor-Based Heterostructures

The 1986 TMS Northeast Regional Conference will deal with semiconductor-based heterostructures such as GaAs epitaxially deposited on $\mathrm{Si}$ to create an electro-optic device, or multilayer conductive films for VLSI. The conference, to be held May 1 and 2, 1986, at AT\&T Bell Laboratories, Murray Hill, NJ, is co-sponsored by the Materials Research Society.

Highlight topics will include silicon on insulators, $\mathrm{Ge}$ on $\mathrm{Si}$, epitaxial silicides, amorphous superlattices, compound semiconductors on silicon, compound semiconductor metallization and passivation, and the processing techniques involved in preparing these heterostructures. Other issues to be discussed will be multilevel metallization schemes for VLSI, strained-layer superlattices, nanocomposite materials, interfacial growth, pseudomorphic growth, ohmic contact to semiconductors, and phase transformations in thin film structures.

Contact the conference chairman, Martin L. Green, AT\& T Bell Laboratories, Murray Hill, NJ 07974; telephone (201) 582-3000.

\section{Conference on Low Energy Ion Beams}

MRS has announced its co-sponsorship of the Conference on Low Energy Ion Beams to be held April 7-10, 1986, at the University of Sussex, Brighton, UK. The conference chairman is Prof. William A. Grant of the University of Salford, UK., and the organizing committee is drawn from members of the Atomic Collisions in Solids Group of the Institute of Physics, London.

Papers are invited in the following areas: ion sources; excitation, ionization, and charge transfer; ion optics and beam transport; high current and large area beams; accelerators, ion implantation; ion-assisted deposition; sputter profiling; microbeams; low-energy ion beams for surface analysis; and ion beam and plasma etching.

Invited speakers include: G. Dearnaley (Harwell), J. Van der Berg (UMIST) D. Briggs (ICI), R. G. Forbes (University of Surrey), D. G. Armour (University of Salford), P. C. Zalm (Philips,) J.J Cuomo (IBM), and J. Ishikawa (Kyoto).

Contact Prof. William A. Grant, Department of Electronic and Electrical Engin-

eering, University of Salford, Salford M5 4WT, U.K. of The Meetings Office, Institute of Physics, 47 Belgrade Square, London SW1X 8QX, UK.

MRS members are entitled to special registration rates.

\section{FMS Sponsors Electronic Materials Workshop}

The Federation of Materials Societies (FMS) is sponsoring a workshop on "Electronic Materials: A Key to U.S. Competitiveness" in Washington, DC, February 25-27, 1986 For this workshop, electronic materials are defined as materials of current and future importance in the development and production of electronic components and devices. The materials include (but are not limited to) semiconductors, dielectrics, magnetic, piezoelectric, opto-electronic materials, and optical fibers. The materials may be in the single crystal, polycrystalline, or amorphous state. Also of interest are materials used in packaging electronic components and devices

The workshop will generate a position paper on the following issues:

- Why are electronics a key to U.S. competitiveness?

- What is the present position of U.S. electronic materials technology?

- What can we do in the U.S. to maintain (or regain) a competitive position in electronic materials technology?

Contact Betsy Houston, Federation of High Brightness Electron Sources $5 \mathrm{eV}$ to $100 \mathrm{keV}$

High Brightness Ion Sources

UHV Electrostatic Optics, Power Supplies

Charge Neutralization Systems

Accessories for SEM, MBE, ESD, SIMS, AUGER, $e^{-}$Lithography Custom UHV Apparatus

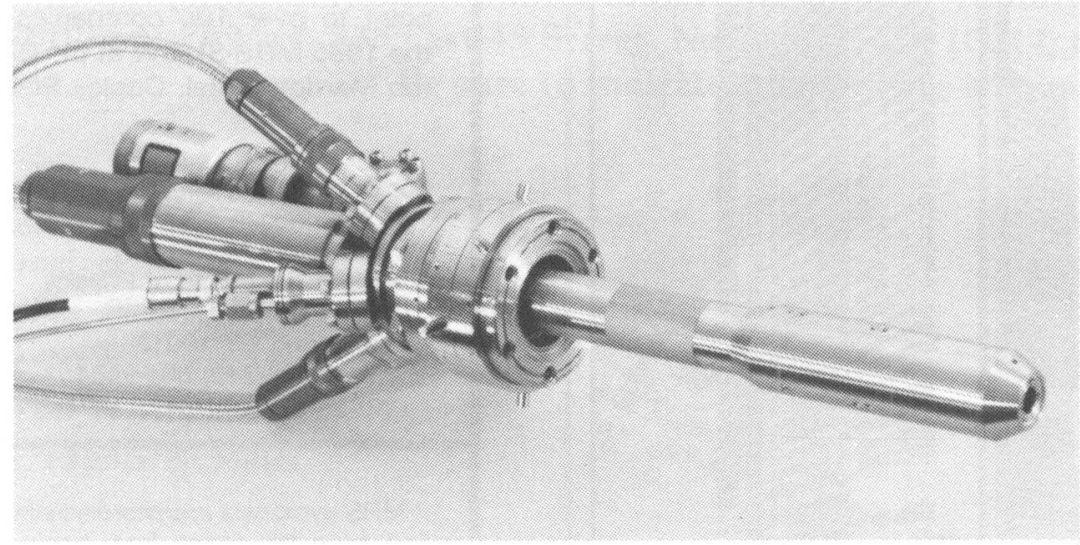

UP TO $20 \mathrm{keV}$ AVAILABLE ON $70 \mathrm{~mm}\left(2 \frac{3}{4} \mathrm{in}.\right)$ CONFLAT
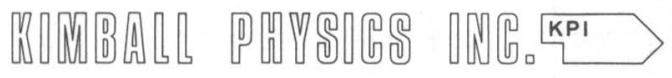

KIMBALL HILL ROAD

WILTON, NH 03086

Washington, DC 20036

\section{Role of Interfaces is Topic of Ceramic Microstructures ' 86}

An international conference on "Ceramic Microstructures '86: Role of Interfaces" will be held on the Berkeley campus of the University of California, July 28-31, 1986. This conference is the third in a 10-year interval series that started in 1966. It is also the $22 \mathrm{nd}$ in a series of University Conferences on Ceramic Sciences

The opening session will introduce the role of interfaces and review the current status. Other introductory talks will overview ceramic microstructures, electric properties and microstructures, and mechanical properties and microstructures. Subsequent sessions will present papers on characterization of microstructures, microstructure production, and the effects of interfaces on electrical properties and on mechanical properties.

To submit a paper or register to attend, contact either Joseph A. Pask or Anthony G. Evans, Department of Materials Science and Materials Engineering, University of California, Berkeley, California 94720. 


\section{YOUR SUBSCRIPTION TO MATERIALS LETTERS IS EXPIRING}

As a member of the Materials Research Society, you have been receiving a complimentary subscription to Materials Letters which will expire at the end of Volume III (Volume III will be completed in the fall). MRS has arranged a way for you to continue your subscription by negotiating a special low rate with the publisher. To receive Volume IV of Materials Letters you need only pay $\$ 17.50$. Personal subscriptions to Materials Letters are available only to MRS members, and this special rate enables you to continue to receive this publication at minimal cost.

This new optional subscription program enables the Society to provide continuity to the members who have expressed a desire to continue receiving Materials Letters, while expanding its dues-supported benefits package to include a subscription to the new Journal of Materials Research beginning in 1986.

\section{REMEMBER}

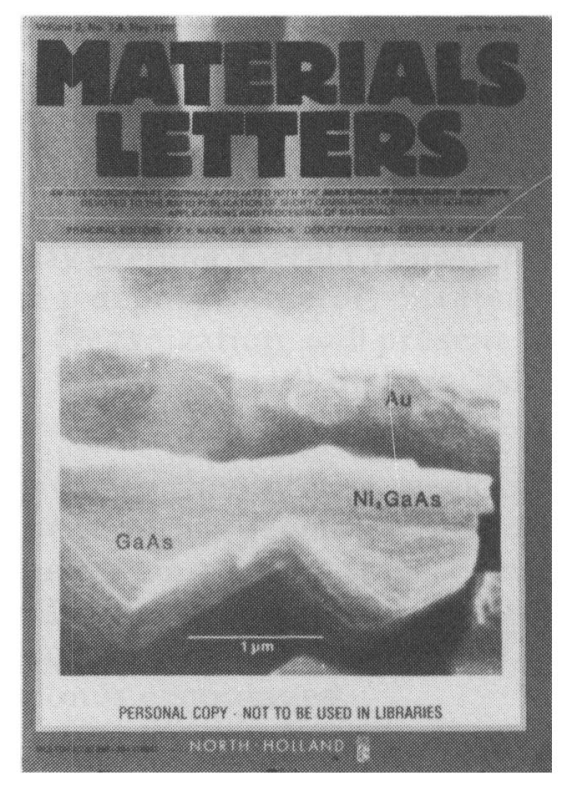

As an MRS member in 1986, you will automatically receive Journal of Materials Research as part of your membership dues, but can also maintain an exclusive personal subscription* to Materials Letters at a small charge. Return this order form immediately to the Materials Research Society with your payment of $\$ 17.50$ if you wish to receive Volume IV of Materials Letters.

*Institutional subscriptions for your library must be obtained through the publisher, Elsevier Science Publishers B. V., Journal Department, P.O. Box 211, 1000 AE Amsterdam, The Netherlands.

\section{SUBSCRIPTION TO VOLUME IV OF MATERIALS LETTERS}

Name

Organization

City State Zip/Postal Code

Country

Please enter my personal subscription to Materials Letters for Volume IV. I am a member of MRS and enclose my subscription payment of $\$ 17.50$

Return to: Materials Letters Subscription, Materials Research Society, McKnight Road, Suite 327, Pittsburgh, PA 15237; telephone (412) $367-3003$. 